\title{
Surgical Management of Split Depression Fracture of The Lateral Tibial Plateau
}

\author{
Seleem Hamed Almosalamy, Mohsen Mohamed Abdo Mar'ei, \\ Ahmed Mostafa El Naggar, Ayhaab Abuzayd Salim Mohammed* \\ Department of Orthopedic Surgery, Faculty of Medicine, Zagazig University, Egypt \\ *Corresponding author: Ayhaab Abuzayd Salim, Mobile: (+20)1023768824, E-Mail: ehababozeed1987@gmail.com
}

\begin{abstract}
Background: Tibial plateau fractures are one of the commonest intra-articular fractures resulting from indirect coronal or direct axial compressive forces. Fractures of tibial plateau constitute $1 \%$ of all fractures and $8 \%$ of fractures in the elderly.

Objective: In the present study, we aimed to prevent the development of osteoarthritis and to correlate the radiological findings with this type of tibial plateau fracture.

Patients and methods: This study was an interventional study, where 18 patients were conducted with tibial plateau fracture Schatzker type 2 and were operated in the Department of Orthopedics, Faculty of Medicine, at Zagazig University Hospital.

Results: Most of cases (55.6\%) were operated upon 2 days after occurrence of fracture, followed by $27.8 \%, 16.6 \%$ were operated upon after 7 days and 10 days respectively. Seventeen (94.4\%) cases were fixed by buttress plate while 1 case $(5.6 \%)$ was fixed by proximal tibial plate and 16 cases $(88.9 \%)$ needed bone graft. Significant improvement in time regard function score (knee society score) and radiological score (Rasmussen Assessment score) were found. No complication was found in $66.7 \%$ of studied group; $16.7 \%$ had infection, $11.1 \%$ had valgus deformity and only one case $5.6 \%$ had stiffness.
\end{abstract}

Conclusion: It could be concluded that the surgical management of tibial plateau fractures is challenging and gives excellent anatomical reduction and rigid fixation to restore articular congruity, facilitate early knee motion by reducing post-traumatic osteoarthritis and thus achieving optimal knee function.

Keywords: Surgical Management, Split Depression Fracture, Lateral Tibial Plateau

\section{INTRODUCTION}

Tibial plateau fractures are one of the commonest intra-articular fractures resulting from indirect coronal or direct axial compressive forces. Fractures of tibial plateau constitute $1 \%$ of all fractures and $8 \%$ of fractures in the elderly ${ }^{(\mathbf{1})}$.

These fractures encompass many and varied fracture configurations that involve the medial condyle $(10-23 \%)$, lateral condyle (55-70\%) or both (11-30\%) with differing degrees of articular depression and displacement ${ }^{(2)}$.

In case of improper restoration of the plateau surface and the axis of the leg, these fractures could lead to development of premature osteoarthritis, injury in ligaments, as well lifelong pain and disability ${ }^{(3)}$. Tibial plateau fractures may be accompanied by meniscal and ligamentous injuries to the knee too ${ }^{(4)}$.

For assessment of the initial injury, planning management and prediction of prognosis, orthopedic surgeons widely use the Schatzker classification system, which divides tibial plateau fractures into six types. Each increasing numeric category specifies increased level of energy imparted to bone thereby increasing severity of fracture ${ }^{(4)}$.

First four are unicondylar and type V and VI are bicondylar. Each fracture's pattern in Schatzker classification helps to direct orthopedic surgeons to adopt appropriate treatment modality ${ }^{(5)}$.
In the surgical treatment of split depression fractures (Schatzker type II) of the lateral tibial plateau (which constitute more than $25 \%$ of all tibial plateau fractures) the goal is reduction of the articular surface and stable fixation. The subchondral defect in the metaphysis is usually grafted with bone from the iliac crest to support the elevated articular surface ${ }^{(6)}$.

The advantages of surgical treatment include early mobilization of the knee, rapid bone union, and better quality of reduction ${ }^{(7)}$.

Disadvantages are pain symptoms ${ }^{(\mathbf{8})}$ and other donor site complications ${ }^{\left({ }^{9}\right)}$ as well as resorption of the graft with subsequent loss of reduction. Nonresorbable, osteoconductive bone substitutes may therefore be an advantage over autogenous bone grafts (10).

In the present study, we aimed to prevent the development of osteoarthritis and to correlate the radiological findings with this type of tibial plateau fracture.

\section{PATIENTS AND METHODS}

This interventional study included a total of 18 patients presented with tibial plateau fracture Schatzker type 2 and were operated upon in the Department of Orthopedics, Faculty of Medicine, Zagazig University Hospital. 


\section{Inclusion criteria:}

Patients above 18 years of either sex, patients with split depressed fracture of the lateral tibial plateau, and radiological diagnosis of fractures with classification based on Schatzker's classification fractures type II lateral tibial plateau. Hemoglobin is at least $10 \mathrm{~g} / \mathrm{dl}$.

Exclusion criteria: Patients aged less than 18 years who were medically unfit for the surgery, compound tibial plateau fracture, and patients classified with Schatzker's classification Type I, III, IV, V and VI.

\section{All patients were subjected to:}

Assessment, counseling, clinical evaluation (history, general examination, and local examination), radiological evaluation and preoperative preparation of the patient.

Preoperative investigations including $\mathrm{CBC}$, PT, PTT, RBS, CRP, liver function tests and kidney function tests. Chest X-ray. ECG for patients more than 40 years old.

\section{Clinical evaluation:}

a) History: including name, age, sex, mechanism of injury, time of the injury, previous medical history of associated disease, address, and phone number.

b) General examination: The ER patients are examined according to the Advanced Trauma Life Support (ATLS) protocol and all patients received assessment of the head, neck, chest, pelvis, abdomen, and any suspected other limb injuries.

c) Local examination:

(1) Inspection: Inspection of the soft tissue: skin integrity, swelling, abrasions, skin bullae, contusions, ecchymosis, and any open wound should be addressed according to its extent and size.

(2) Palpation: Palpation should be applied for site of tenderness, crepitus at fracture site.

\section{Neurovascular examination:}

This includes assessment of the posterior tibial and dorsalis pedis pulsation, ankle movements and sensation around the foot.

\section{Radiological evaluation:}

(1) X- ray: All the patients had X-ray of AP and Lateral views of the knee and Leg. X-ray requested for any other suspected injuries including the skull, neck, chest, pelvis, spine and any other limb injuries. The fractures are classified using Shatzker classification.

(2) CT scan: CT scan of the affected knee and tibia was requested including sagittal, axial, coronal and 3D CT scan.

(3) MRI: MRI was done for patients if it was requested. The role of MRI in management of proximal tibial fractures is evolving.

(4) Doppler: The Doppler was requested in three cases we suspected vascular injury.

\section{Ethical consent:}

An approval of the study was obtained from Zagazig University academic and ethical committee. Every patient signed an informed written consent for acceptance of the operation. This work has been carried out in accordance with The Code of Ethics of the World Medical Association (Declaration of Helsinki) for studies involving humans.

\section{Statistical Analysis}

Data collected throughout history, basic clinical examination, laboratory investigations and outcome measures coded, entered, and analyzed using Microsoft Excel software. Data were then imported into Statistical Package for the Social Sciences (SPSS version 20.0) (Statistical Package for the Social Sciences) software for analysis. According to the type of data, qualitative result was represented as number and percentage, quantitative result was represented by mean $\pm \mathrm{SD}$, the following tests were used to test differences for significance; difference and association of qualitative variable by $\mathrm{Chi}$ square test $\left(\mathrm{X}^{2}\right)$. Differences between quantitative independent groups by $\mathrm{t}$ test paired by paired $\mathrm{t}$. $\mathrm{P}$ value was set at $<0.05$ for significant results $\&<0.001$ for high significant result.

\section{RESULTS}

The mean age was distributed as $\mathbf{4 4 . 1 1} \pm \mathbf{8 . 5 1}$ with minimum 28 and maximum 59 years. Most of cases were between age group (41-50 years) $38.9 \%$ and (31-40 years) 33.3\%. Sex distributions were mostly male $77.8 \%$ and females $22.2 \%$. Most of cases (55.6\%) were operated upon 2 days after occurrence of fracture, followed by $27.8 \%, 16.6 \%$ operated upon after 7 days and 10 days respectively. 
Table (1): Age and sex distribution, fracture incidence in various age groups and Time interval between fracture occurrence and operation among studied group $(\mathrm{N}=18)$

\begin{tabular}{|c|c|c|c|}
\hline & & \multicolumn{2}{|c|}{ Age (years) } \\
\hline \multicolumn{2}{|l|}{ Mean \pm SD } & \multicolumn{2}{|c|}{$44.11 \pm 8.51$} \\
\hline \multicolumn{2}{|l|}{ Median (Range) } & \multicolumn{2}{|c|}{$46.0(28-59)$} \\
\hline & & $\mathbf{N}$ & $\%$ \\
\hline \multirow{3}{*}{ Sex } & Male & 14 & 77.8 \\
\hline & Female & 4 & 22.2 \\
\hline & Total & 18 & 100.0 \\
\hline \multirow{4}{*}{ Fracture incidence in various age } & 21-30 & 1 & 5.6 \\
\hline & $31-40$ & 6 & 33.3 \\
\hline & 41-50 & 7 & 38.9 \\
\hline & $51-60$ & 4 & 22.2 \\
\hline \multirow{3}{*}{$\begin{array}{l}\text { Time interval between fracture } \\
\text { occurrence and operation }\end{array}$} & 2 days & 10 & 55.6 \\
\hline & 7 days & 5 & 27.8 \\
\hline & 10 days & 3 & 16.6 \\
\hline
\end{tabular}

Buttress plate was used for fixation in 17 cases while 1 case was fixed by proximal tibial plate. Bone graft was needed in 16 cases.

Table (2): Various surgical methods and bone graft among studied group

\begin{tabular}{|c|c|c|c|}
\hline & & $\mathbf{N}$ & \% \\
\hline \hline \multirow{2}{*}{$\begin{array}{c}\text { Type } \\
\text { of plate }\end{array}$} & Buttress plate & 17 & 94.4 \\
\cline { 2 - 4 } $\begin{array}{c}\text { Bone } \\
\text { graft }\end{array}$ & Proximal tibial plate & 1 & 5.6 \\
\cline { 2 - 4 } & Needed & 16 & 88.9 \\
\hline
\end{tabular}

were 6 weeks

Regarding period of immobilization, $77.8 \%$ were less than 10 days and $16.7 \%$ were 3 weeks and only $5.6 \%$

Table (3): Period of immobilization distribution

\begin{tabular}{|c|c|c|c|}
\hline \multicolumn{2}{|c|}{} & $\mathbf{N}$ & \% \\
\hline \hline \multirow{3}{*}{$\begin{array}{c}\text { Period of } \\
\text { immobilization }\end{array}$} & <10day & 14 & 77.8 \\
\cline { 2 - 4 } & 3week & 3 & 16.7 \\
\cline { 2 - 4 } & 6week & 1 & 5.6 \\
\cline { 2 - 4 } & Total & 18 & 100.0 \\
\hline
\end{tabular}

Significant improvement in time regard function score (knee society score)

Table (4): Knee Society Score distribution at different times among studied group

\begin{tabular}{|c|c|c|c|}
\hline & Knee Society Score 3 M & Knee Society Score 6 M & \multirow{2}{*}{ P value } \\
\hline \hline Mean \pm SD & $79.0 \pm 7.17$ & $81.44 \pm 7.58$ & \multirow{2}{*}{0.49} \\
\hline Median (Range) & $\mathbf{8 1 . 0}(63-91)$ & $\mathbf{8 4 . 0}(65-93)$ & \\
\hline
\end{tabular}

Significant improvement in time regard radiological score (Rasmussen Assessment score)

Table (5): Rasmussen Assessment score distribution at different times among studied group

\begin{tabular}{|c|c|c|c|}
\hline & $\begin{array}{c}\text { Rasmussen Assessment } \\
\text { criteria 3 M }\end{array}$ & Rasmussen Assessment criteria 6 M & $\begin{array}{c}\text { P } \\
\text { value }\end{array}$ \\
\hline \hline Mean \pm SD & $8.5 \pm 1.46$ & $8.77 \pm 1.47$ & \multirow{2}{*}{0.399} \\
\hline $\begin{array}{c}\text { Median } \\
\text { (Range) }\end{array}$ & $9.0(6-10)$ & $9.0(6-10)$ & \\
\hline
\end{tabular}


Table (6): Radiological Rasmussen Assessment distribution

\begin{tabular}{|c|c|c|c|}
\hline & & $\mathbf{N}$ & $\%$ \\
\hline \multirow{3}{*}{ Rasmussen Assessment criteria 3M level } & Fair & 3 & 16.7 \\
\hline & Good & 7 & 38.9 \\
\hline & Excellent & 8 & 44.4 \\
\hline \multirow{4}{*}{ Rasmussen Assessment criteria $6 \mathrm{M}$ level } & Fair & 3 & 16.7 \\
\hline & Good & 7 & 38.9 \\
\hline & Excellent & 8 & 44.4 \\
\hline & Total & 18 & 100.0 \\
\hline
\end{tabular}

There was no complications were reported in $66.7 \%$ of studied group, $16.7 \%$ had infection. $11.1 \%$ had valgus deformity and only one case $5.6 \%$ had stiffness.

Table (7): Complications distribution among studied group

\begin{tabular}{|c|c|c|c|}
\hline & & $\mathbf{N}$ & $\mathbf{\%}$ \\
\hline \hline \multirow{4}{*}{ Complications } & $\mathbf{N o}$ & 12 & 66.7 \\
\cline { 2 - 4 } & Valgus deformity & 2 & 11.1 \\
\cline { 2 - 4 } & Infection & 3 & 16.7 \\
\cline { 2 - 4 } & Stiffness & 1 & 5.6 \\
\cline { 2 - 4 } & Total & 18 & 100.0 \\
\hline
\end{tabular}

\section{DISCUSSION}

In the present study, most fractures occurred between the age of 41 and 50 years $(38.9 \%), 31$ and 40 years $(33.3 \%)$ with the mean age 44.11 years. This came in agreement with Vasanad et al. ${ }^{(11)}$ who found that the majority of fractures occurred between the age of 20 and 60 years with maximum incidence in the productive age group of 31-40 years (50.25\%).

Honkonen ${ }^{(12)}$ also showed age incidence 20 60 years with an average of 39.8 years which correlates with the present study. Lee et $\boldsymbol{a l} .{ }^{(13)}$ too showed that the average age of tibial plateau fractures in patients was 42 years. Albuquerque et al. (14) observed that $71 \%$ of injuries occurred in those aged 30-60 years, with maximum frequency between 40-49 years. High energy injuries are more common in youngsters and low energy fractures in elderly patients (6).

In the present study, we studied 18 cases of type II tibial plateau fractures while other types were excluded. In our study the cause of injury was RTA in $72.2 \%$ of cases; and $27.8 \%$ of cases the cause was fall from height (FFH). Only two cases was associated by fracture of neck of fibula and one case associated by fracture of spine and another case associated by fracture of pubic remi.

In agreement with our study, Shen et al. (15) found that causes of injury: $18.2 \%$ of cases were due to traffic accidents, $54.5 \%$ of cases due to bicycle falls, and 27.3 of cases due to high-level fall injuries.

In the present study, majority of cases treated by Buttress plates (94.4\%) and needed bone graft (88.9\%). This came in agreement with Shen et al. ${ }^{(15)}$ study, in which the bone defect below the articular surface after the reduction of the lateral tibial plateau collapse area was filled with bone graft in majority of cases. Also, Vasanad et al. ${ }^{(11)}$ found that majority of cases treated by ORIF with buttress plate with bone grafting.

In the present study, regarding period of immobilization $77.8 \%$ were less than 10 days and $16.7 \%$ were 3 weeks and only $5.6 \%$ were 6 weeks. In agreement with our study, Vasanad et al. ${ }^{(11)}$ found that regarding period of immobilization $75 \%$ were less than 10 days and $15.6 \%$ were 3 weeks and only $9.3 \%$ were 6 weeks.

Regarding to knee society score, we achieved $55.6 \%$ excellent result, $33.3 \%$ good results (overall $88.9 \%$ acceptable results) and $11.1 \%$ fair results after 6 months of follow- up. This came in agreement with Vasanad et al. ${ }^{(11)}$ who found that $44 \%$ of patients had excellent result and $44 \%$ had good results (overall $88 \%$ acceptable results) with our standard surgical care using various standard fixation methods.

Rohra et al ${ }^{(\mathbf{1 6})}$ found out of 34 patients twenty four patients $(70.59 \%)$ had excellent, 8 patients (23.53\%) had good and 1 patient $(2.94 \%)$ each of poor and fair functional knee society score.

In the present study, we used Rasmussen radiological criteria to evaluate the effect of fracture reduction and fixation. It was excellent in 8 patients (44.4\%), good in 7 patients $(38.9 \%)$ and fair in 3 patients $(16.7 \%)$ after 6 months of follow-up.

Shen et al. ${ }^{(15)}$ found that the results were excellent in 4 cases and good in 3 cases; therefore, $100 \%$ of results were excellent or good. This 
difference may be due to different inclusion criteria and different approaches.

In the present study, $66.7 \%$ of studied group had no complication $16.7 \%$ ( 3 cases) had infection, $11.1 \%$ (2cases) had valgus deformity and only one case $5.6 \%$ (1 case) had stiffness. Superficial infection was presented in two patients and after systematic antibiotics one of them improved and the other had recurrent attacks of infections for six months then removal of the plate and debridement was done to eradicate the infection. And one patient was presented by deep infection from the start and after repeated sessions of antibiotics he improved. The majority of cases with complications were older, the time interval between fracture occurrence and operation was 10 days and they were due to FFH.

This came in agreement with $\mathbf{Y u}$ and Fenglin (17) in their study on 325 tibial plateau fractures doing plating, who found that one of the most common complications was infection, the rate of infection was 4.6\%, while Metcalf et al. ${ }^{(\mathbf{1 8})}$ found in their systematic review that: the rates of infection in patients doing plating were $7.3 \%$.

In the present study, in the final imaging examination all fractures healed, and no patients developed symptoms of non-union. This came in agreement with Pires et al. ${ }^{(19)}$ who found that all fractures healed, and no patients developed symptoms of non-union.

\section{CONCLUSION}

It could be concluded that surgical treatment when indicated (particularly in depressed and displaced fractures) is advantageous to get a stable knee. The surgical management of tibial plateau fractures is challenging and gives excellent anatomical reduction $\&$ rigid fixation to restore articular congruity, facilitate early knee motion by reducing post-traumatic osteoarthritis and thus achieving optimal knee function.

\section{Financial support and sponsorship: Nil.}

\section{Conflict of interest: Nil.}

\section{REFERENCES}

1. Arun K, Madhuchandra P, Raju K et al. (2018): Functional outcome of tibial plateau fractures treated with locking compression plates. Journal of Indian Orthopaedic Rheumatology Association, 4(1):14-17

2. Koval K, Hulfut D (1995): Tibial plateau fracture: evaluation and treatment. J Am Acad Orthop Surg., 3(2):86-94.

3. Wang S, Gao Y, Wang J et al. (2011): Surgical approach for high-energy posterior tibial plateau fractures. Indian J Orthop., 45(2):125-31.

4. Markhardt B, Gross J, Monu J (2009): Schatzker Classification of Tibial Plateau Fractures: Use of CT and MR Imaging Improves Assessment. Radio Graphics, 29:585-97.

5. Sonkar D, Bansal A, Shukla J et al. (2015): Functional Outcome of Locking Compression Plate Osteosynthesis in Schatzker's Type V and VI Tibial Plateau Fractures. Journal of Evolution of Medical and Dental Sciences, 4(89): 15450-15454.

6. Zeltser D, Leopold S (2013): Classifications in brief: Schatzker classification of tibial plateau fractures. Clin Orthop Relat Res., 471(2):371-74.

7. Jónsson B, Mjöberg B (2009): Surgical treatment of depression fractures of the lateral tibial plateau using porous titanium granules. Ups J Med Sci., 114(1): 5254.

8. Frigg R, Appenzeller A, Christensen $R$ et al. (2001): The development of the distal femur Less Invsive Stabilization System (LISS). Injury, 32: 24-31.

9. Goulet J, Senunas L, DeSilva G et al. (1997): Autogenous iliac crest bone graft. Complications and functional assessment. Clin Orthop Relat Res., 339:7681.

10. Arrington E, Smith W, Chambers H et al. (1996): Complications of iliac crest bone graft harvesting. Clin Orthop Relat Res., 329:300-9.

11. Vasanad G, Antin S, Akkimaradi R et al. (2013): Surgical management of tibial plateau fractures-a clinical study. Journal of Clinical and Diagnostic Research, 7(12): 3128-33.

12. Honkonen $S$ (1995): Degenerative arthritis after tibial plateau fractures. J Orthop Trauma, 9(4):273-7.

13. Lee $M$, Lin $K$, Renn $\mathbf{J}$ (2014): Comparison of outcome of unilateral locking plate and dual plating in the treatment of bicondylar tibial plateau fractures. Orthop Surg Res., 9(62): 1-5.

14. Albuquerque R, Hara R, Prado J et al. (2013): Epidemiological study on tibial plateau fractures at a level I trauma center. Acta Ortopédica Brasileira, 21(2): 109-115

15. Shen Q, Zhang J, Xing G et al. (2019): Surgical Treatment of Lateral Tibial Plateau Fractures Involving the Posterolateral Column. Orthopaedic Surgery, 11(6): 1029-1038.

16. Rohra N, Suri H, Gangrade K (2016): Functional and Radiological Outcome of Schatzker type V and VI Tibial Plateau Fracture Treatment with Dual Plates with Minimum 3 years follow-up: A Prospective Study. J Clin Diagn Res., 10(5): 5-10.

17. Yu L, Fenglin $Z$ (2015): High-energy tibial plateau fractures: external fixation versus plate fixation. European Journal of Orthopaedic Surgery \& Traumatology, 25 (3): 411-23.

18. Metcalfe D, Hickson C, McKee L et al. (2015): External versus internal fixation for bicondylar tibial plateau fractures: systematic review and meta-analysis. Journal of Orthopaedics and Traumatology, 16(4):27585.

19. Pires R, Giordano V, Wajnsztejn A et al. (2016): Complications and outcomes of the transfibular approach for posterolateral fractures of the tibial plateau. Injury, 47: 2320-2325. 